\title{
Self-reported outcomes of aural rehabilitation for adult hearing aid users in a South African context
}

\author{
Elaine Pienaar \\ Natalie Stearn \\ Department of Communication Pathology, University of Pretoria
}

De Wet Swanepoel

Department of Communication Pathology, University of Pretoria; Callier Center for Communication Disorders, University of Texas, Dallas, USA

Correspondence to: D Swanepoel (dewet.swanepoel@up.ac.za)

\begin{abstract}
Hearing impairment has far-reaching consequences for affected individuals, in terms of quality of life indicators. In the public health care sector of South Africa the hearing-impaired population is faced with limited aural rehabilitation services. This study evaluated self-reported outcomes of aural rehabilitation in a group of adults in the public health care sector with a standardised outcomes measurement tool (IOI-HA). Sixty-one participants were included ( $44 \%$ male; sample mean age 69.7 years) through face-to-face or telephonic interviews. Results revealed that the average perceived outcome of participants ( 5 = best outcome; 1 = poorest outcome) was positive across all domains of the inventory including daily use of hearing aids (4.3); benefits provided by hearing aids (4.3); residual activity limitation (3.9); satisfaction with hearing aids (4.5); residual participation restriction (4.0); impact of hearing difficulties on others (4.6); and changes in quality of life (4.5). Statistically significant relationships for daily use of hearing aids, degree of hearing loss, type of hearing aids fitted, and the perceived benefit from hearing aids in difficult listening environments $(p<0.05)$ were evident. Adult aural rehabilitation for hearing loss in a public health care facility, even without optimal hearing aid fittings, was effective in providing positive perceived outcomes comparable to similar studies in developed countries. The findings advocate for the initiation of affordable and sustainable aural rehabilitation services in developing countries despite apparent resource limitations.
\end{abstract}

Keywords: aural rehabilitation, self-reported outcomes, developing countries, public health care sector, IOI-HA

The 2005 World Health Organization estimates indicated that 278 million people are affected by disabling hearing loss, two-thirds of whom live in developing countries (WHO, 2005). It is therefore not surprising that hearing loss is a significant contributor to the global burden of disease on individuals, families, communities and countries (WHO, 2005). The number of people with disabling hearing impairment is expected to progressively increase as a result of the increase in world population and a greater life expectancy. Decisive public health action at primary, secondary and tertiary levels should be prioritised to prevent avoidable hearing loss and ensure optimal outcomes for those living with the condition (WHO, 2001).

The effects of hearing loss are pervasive and far-reaching for individuals and their families. Hearing loss affects social participation, emotional and behavioural well-being, employment status and quality of life (Northern \& Downs, 2002). Fortunately, the effects of hearing loss can be limited by effective amplification and aural rehabilitation. The first and fundamental step in the aural rehabilitation process involves amplification. A hearing aid is the primary tool in the rehabilitation process (Alpiner \& McCarthy, 2000), and aims to restore hearing sensitivity to a normal hearing level (Gagné, 2000). Aural rehabilitation also goes beyond this and assists individuals to restore or optimise participation in activities considered restrictive by the hearing-impaired individual (Gagné, 2000).

As part of clinical procedure, feedback about aural rehabilitation can be obtained by self-reported outcome assessments. Outcome assessments should evaluate the degree to which hearing aids assist individuals to overcome their hearing difficulties, and determine their level of functioning (Danermark, Cieza, Gange, Gimigliano, Granberg, Hickson et al., 2010). While objective measures, such as speech-recognition scores, measure the benefits provided by the amplification and other technical features of a hearing aid, self-reporting has the potential to subjectively evaluate the entire process of aural rehabilitation as experienced by the affected individual (Vestergaard, 2006). The International Outcome Inventory for Hearing Aids (IOI-HA) questionnaire is a commonly used self-reporting measure that consists of seven domains related to hearing aid fitting outcomes. These include: (i) hearing aid use as number of hours per day; (ii) benefit related to difficult listening situations; (iii) residual activity limitations related to the hearing loss; (iv) satisfaction with the hearing aids; $(v)$ residual participation restrictions in daily life activities even with amplification; ( $v i$ impact of hearing loss on others; and (vii) quality of life improvements after amplification (Hickson, Clutterbuck $\&$ Khan, 2010). The IOI-HA is especially useful since comparisons can be made across studies because a number of published reports have used the instrument. A limitation of the instrument is that it does not differentiate between listening situations or include aspects of satisfaction related to the hearing aid or the service provided (Hickson et al., 2010). Despite widespread use of the IOI-HA questionnaire, there is currently no universal outcomes measure for aural rehabilitation. As a result, the World Health Organization International Classification of Functioning branch is currently in the process of developing a core set of outcomes of functioning for individuals with hearing loss (Danermark et al., 2010).

The growing emphasis on evidence-based audiological rehabilitation means that such outcome measures are becoming increasingly important (Gagné, 2000). Assessing patient satisfaction is an essential part of modern patient-orientated health care services (Danermark et al., 2010). Self-reported outcome measures of aural rehabilitation are therefore of great value and importance to assist in identifying the patient's need for services, highlight expectations that are met through aural rehabilitation, and provide insight into the impact of the impairment on the patient's functioning in daily life (Danermark et al., 2010; Olusanya, 2004). As a result these measures of aural rehabilitation outcomes are prioritised within the health care systems of developed countries. Reports from countries such as The Netherlands, UK, Australia and the USA indicate significant self-perceived improvements in outcomes as a result of aural rehabilitation and are often required to demonstrate the efficacy of audiological services (Kramer, Goverts, Dreschler, Boymans \& Festen, 2002; Stephens, 2002; Cox \& Alexander, 2002; Williams, Johnson \& Danhauer, 2009; Hickson et al., 2010).

In contrast, measuring the efficacy of aural rehabilitation services in developing countries is not prioritised (WHO, 2006; Olusanya, Luxn \& Wirz, 2004). Developing countries are economically less developed, determined by factors such as low human and social development 
in terms of education, health care and life expectancy (World Bank, 2004). Overcrowding, malnutrition and poverty often characterise the living conditions in developing countries (Olusanya, 2005). Because of competing demands from diseases with high mortality rates such as HIV/AIDS, the focus of health care systems in developing countries is on life-threatening diseases, and little or no support is provided for non-communicable conditions affecting quality of life such as hearing loss (Olusanya, 2004).

Owing to the lack of services for hearing-impaired individuals in developing countries, the research on self-reported outcomes of aural rehabilitation in these countries is very limited. The first such published report, conducted by Olusanya (2004) on the self-reported outcomes of aural rehabilitation in Nigeria, indicated that hearing aid users considered the devices to be beneficial and desirable in all specified domains of the IOI-HA. These findings compared favourably with those of developed countries in almost all domains, indicating that hearing aid users from developed and this developing country may receive similar benefit from aural rehabilitation (Kramer et al., 2002; Stephens, 2002; Cox \& Alexander, 2002). The results further suggested that if appropriate conditions for hearing aid services are provided, aural rehabilitation in a developing country may reduce disability and enhance functionality in crucial quality of life domains (Olusanya, 2004).

Based on these studies in developed countries and in a single report from a developing country (Kramer et al., 2002; Stephens, 2002; Cox \& Alexander, 2002; Olusanya, 2004), the current research project aimed to investigate the outcomes of aural rehabilitation in South Africa by means of the IOI-HA questionnaire. The use of this widely used device ensured that it could be compared with previous findings from other countries. The unique characteristics of developing countries require the investigation of self-reported outcomes of aural rehabilitation within the contextual realities faced in these settings. Favourable outcomes of aural rehabilitation in developing countries may serve to highlight the importance of early identification and intervention of hearing impairment despite the burden of other challenges that characterise these countries.

\section{Method}

The main aim of this study was to describe the self-reported outcomes for a group of adult hearing aid users in South Africa using the IOIHA. The outcomes were described in terms of daily use of hearing aid(s), benefits (improved activity) provided by hearing aid(s), residual activity limitation, satisfaction provided by the hearing aid(s), residual participation restriction, impact of hearing loss on others, and quality of life.

\section{Research context}

The study was conducted at a tertiary hospital in Gauteng, South Africa. Tertiary hospitals form part of the public health care sector, which serves approximately $85 \%$ of the population (National Treasury Department, Republic of South Africa, 2005). The public health care sector serves the developing portion of the population who cannot afford private health care insurance and only utilises $39 \%$ of the country's total health care expenditure (National Treasury Department, Republic of South Africa, 2005). This tertiary hospital included ear, nose, and throat services, diagnostic audiometry, electrophysiological testing and hearing aid fittings. Hearing aid fittings utilised both digital and analogue technology on the State tender.

\section{Participants}

A total of 61 participants, 27 (44\%) male and 34 (56\%) female, were included in this study. Ages ranged between 23 and 91 years with a mean age of 69.7 years. The degree of hearing loss prior to fitting was minimal to moderate ( 26 - $70 \mathrm{dBHL})$ for $23(38 \%)$ and moderate to profound $(>70$ $\mathrm{dBHL})$ for $38(62 \%)$. Thirty-eight participants $(62 \%)$ were fitted with behind-the-ear (BTE) and 23 (38\%) with in-the-ear (ITE) hearing aids. Thirty-two (52\%) and 29 (48\%) participants were fitted with analogue and digital technology hearing aids respectively. Only 18 (30\%) were fitted binaurally, while the rest of the participants (70\%) were fitted monaurally. Most of the participants were fitted monaurally because of financial constraints. The minimum period of time that participants were fitted with hearing aids when interviewed was 2 months and the maximum was 8 months. Table I contrasts the study method and profile of participants for this study compared with similar studies in developed countries (Kramer et al., 2002; Stephens, 2002; Cox \& Alexander, 2002) and a developing country (Olusanya, 2004). Table II outlines the participant selection criteria for the current study.

The aural rehabilitation process for all participants in this study consisted of hearing aid fitting with pre- and post-fitting counselling. Each participant was counselled on the management and maintenance of the hearing aid and having realistic expectations about hearing aid outcomes, as well as how to effectively use his/her hearing aids to ensure optimal communication in daily life activities.

\section{Questionnaire}

A descriptive quantitative survey design in the form of a questionnaire was followed in this study, the International Outcome Inventory for Hearing Aids (IOI-HA), as used in previous studies of this nature (Kramer et al., 2002; Stephens, 2002; Cox \& Alexander, 2002; Olusanya, 2004). This self-reported outcome measurement tool was developed as a product of an International Workshop on Self-Reported Outcome Measures in Audiological Rehabilitation to facilitate co-operation among researchers in diverse health care settings, as well as across national boundaries (Cox, Stephens \& Kramer, 2002). The IOI-HA consists of seven closed-ended questions each targeting a different outcome domain (Cox \& Alexander, 2002; Hickson et al., 2010). South Africa is a developing country, with a diverse collection of people and cultures (Statistics South Africa, 2003), characterised by low human, social and educational development (World Bank, 2004). Within the multi-cultural, multi-racial and multi-lingual context of South Africa, (Statistics South Africa, 2003) the IOI-HA was a valuable research tool, as the wording and construction of the items present minimal literacy and cognitive demands (Cox \& Alexander, 2002).

\section{Data collection and procedures}

Face-to-face and telephonic interviews were used to collect data. Telephonic interviews were done in cases where participants were unable to attend follow-up sessions at the hospital. The researcher clarified any uncertainties or questions participants may have had (De Vos, Strydom, Fouche \& Delport, 2005). The IOI-HA was used in its original English format (Cox \& Alexander, 2002). Although participants were from multi-racial and various language backgrounds, all participants were required to be proficient and comfortable in English.

\section{Analysis}

A scale of 1 - 5 was assigned to each of the 7 items on the IOI-HA, proceeding from the worst outcome (1) to the best outcome (5). This was analysed using descriptive statistics incorporating mean scores and standard deviations. The mean scores for each of the seven domains were compared with other related studies (Kramer et al., 2002; Stephens, 2002; Cox \& Alexander, 2002; Olusanya, 2004) to explore possible cross-country differences. The chi-square test and Fisher's exact test were used to determine whether any statistically significant relationships existed between IOI-HA items and demographic factors. The level of significance was set at $p<0.05$.

\section{Results}

Results are presented in terms of the following: self-reported outcomes of aural rehabilitation based on the seven items on the IOI-HA; the relationships between the degree of hearing loss, the type of hearing aid(s), the daily use of hearing aid(s), the gender of subjects and the benefits perceived by hearing aid(s).

The distribution of responses for the seven self-reported domains of the IOI-HA scale is presented in Figure 1. Results indicated that hearing aid users experienced significant benefit in all seven domains evaluated on the IOI-HA. The average perceived outcome for participants $(5=$ best outcome; 1 = poorest outcome) in each domain was 4.3 for daily use of 
Table I. Profile of participants for the current study and for similar reports from other countries

\begin{tabular}{|c|c|c|c|c|c|}
\hline & $\begin{array}{l}\text { Current } \\
\text { study }\end{array}$ & $\begin{array}{l}\text { Nigeria } \\
\text { (Olusanya, 2004) }\end{array}$ & $\begin{array}{l}\text { UK } \\
\text { (Stephens, 2002) }\end{array}$ & $\begin{array}{l}\text { USA (Cox \& } \\
\text { Alexander, 2002) }\end{array}$ & $\begin{array}{l}\text { Netherlands } \\
\text { (Kramer et al., 2002) }\end{array}$ \\
\hline $\begin{array}{l}\text { Total number of participants } \\
\text { Gender }\end{array}$ & 61 & 99 & 159 & 172 & 505 \\
\hline Male & $27(44 \%)$ & $61(61 \%)$ & $76(47 \%)$ & $57 \%$ & $280(55 \%)$ \\
\hline Female & $34(56 \%)$ & $38(38 \%)$ & $85(52 \%)$ & $42 \%$ & $255(50 \%)$ \\
\hline \multicolumn{6}{|l|}{ Age } \\
\hline Minimum & 23 & 16 & 40 & 26 & 15 \\
\hline Maximum & 91 & 89 & 94 & 98 & 97 \\
\hline Mean & 69.7 & 45.8 & 72.4 & 72 & 64 \\
\hline \multicolumn{6}{|l|}{ Degree of hearing loss } \\
\hline Mild-moderate & $23 \%$ & $34 \%$ & $\begin{array}{l}\text { Mean for better } \\
\text { ear: } 38.8 \mathrm{~dB}\end{array}$ & Not specified & Mean: $67 \mathrm{~dB}$ \\
\hline Moderate-profound ${ }^{*}$ & $38 \%$ & $65 \%$ & $\begin{array}{l}\text { Mean for worse } \\
\text { ear: } 50.6 \mathrm{~dB}\end{array}$ & & \\
\hline \multicolumn{6}{|l|}{ Type of hearing aid } \\
\hline ITE & $23(38 \%)$ & $43(43.4 \%)$ & $5 \%$ & Not specified & Not specified \\
\hline $\mathrm{CIC}$ & 0 & $11(11.1 \%)$ & (ITE \& CIC) & & \\
\hline BTE & $38(62 \%)$ & $33(33.3 \%)$ & $95 \%$ & & \\
\hline Body aids & 0 & $12(12.1 \%)$ & 0 & & \\
\hline \multicolumn{6}{|l|}{ Hearing aids fitted } \\
\hline Monaural & $43(70 \%)$ & $1(1 \%)$ & $99(61 \%)$ & $40 \%$ & $210(41 \%)$ \\
\hline Binaural & $18(30 \%)$ & $98(99 \%)$ & $62(38 \%)$ & $59 \%$ & $295(58 \%)$ \\
\hline \multicolumn{6}{|l|}{ Hearing aid technology } \\
\hline Digital $^{\circ}$ & $29(48 \%)$ & $8(8.1 \%)$ & Not specified & Not specified & Not specified \\
\hline Analogue & $32(52 \%)$ & $91(91 \%)$ & & & \\
\hline \multicolumn{6}{|l|}{ Hearing aid experience } \\
\hline $\begin{array}{l}\text { Minimum } \\
\text { Maximum }\end{array}$ & $\begin{array}{l}2 \text { months } \\
8 \text { months }\end{array}$ & $\begin{array}{l}3 \text { months } \\
12 \text { months }\end{array}$ & Not specified & 1 year & $\begin{array}{l}3 \text { months } \\
1 \text { vear }\end{array}$ \\
\hline Mean & 3.8 months & & & & \\
\hline Research institution & $\begin{array}{l}\text { Public health } \\
\text { sector }\end{array}$ & $\begin{array}{l}\text { Private health } \\
\text { sector }\end{array}$ & $\begin{array}{l}\text { Private health } \\
\text { sector }\end{array}$ & $\begin{array}{l}\text { Private health } \\
\text { sector }\end{array}$ & $\begin{array}{l}\text { Private health } \\
\text { sector (retrospective } \\
\text { study) }\end{array}$ \\
\hline Data collection procedure & Interviews & Interviews & Interviews & Mail & Mail \\
\hline
\end{tabular}

\begin{tabular}{ll}
\hline Table II. Participant selection criteria \\
\hline Criteria & Description \\
Age of participants & Participants were required to be 18 years or older. The study measured the benefits provided by hearing aid(s) for adult \\
hearing aid users. From the age of 18 years a person can give independent consent in South Africa. \\
Participants from different racial, sexual and religious backgrounds participated in this study. This prevented the results \\
of the study from being biased, thereby increasing reliability and validity. \\
Population \\
Hegree of hearing loss \\
included in the study, as the benefits provided by hearing aid(s) vary according to the degree of hearing loss (Tye-Murray, \\
2004). \\
Participants had a unilateral or bilateral, conductive, sensory neural or mixed hearing loss. This increased the sample size, \\
allowing generalisation to be more accurate (De Vos et al., 2005). Furthermore it prevented the study from being biased \\
towards a specific nature of hearing loss. \\
Participants were fitted with analogue or digital technology hearing aid(s), monaurally or binaurally. Any of the following \\
types of hearing aid(s) were fitted: behind-the-ear (BTE), in-the-ear (ITE), in-the-canal (ITC) or completely-in-canal \\
(CIC) hearing aid(s). If only one specific technology and type of hearing aid was singled out, the results would not have \\
been able to be generalised to all hearing aid users. \\
Participants had to be fitted with hearing aid(s) for a period of at least 2 months or longer. Studies suggested that $2-3$ \\
months after fitting is an optimal time frame after which to assess outcomes (Alpiner \& McCarthy, 2000). \\
Participants had to be able to understand and speak English. Given the fact that South Africa is a multi-cultural country \\
with 11 official languages, the International Outcome Inventory for Hearing Aids (IOI-HA) (questionnaire) was used \\
in its original English form (Cox \& Alexander, 2002). The study scope was too limited to translate and validate the \\
questionnaire.
\end{tabular}

hearing aids, 4.3 for benefits provided by hearing aids, 3.9 for residual activity limitation, 4.5 for satisfaction with hearing aids, 4.0 for residual participation restriction, 4.6 for the impact of hearing difficulties on others and 4.5 for changes in quality of life. The highest percentage (72\%) of best outcome scores (5) across all items was for satisfaction with hearing aid(s). A reasonably high (61\%) number of participants indicated the highest or best score (5) for hearing aid(s) daily use and $71 \%$ of participants reported that their hearing aid(s) improved their residual activity level significantly (score 4 and 5). Only two items, benefit and satisfaction, had any scores in the poorest outcome category (1) across the seven domains. Only a very small percentage (2\%) indicated the poorest outcome score (1) in these two categories. 
Results of the chi-square test and Fisher's exact test analysis identified statistically significant relationships between the daily use of hearing aids and the degree of hearing loss $(p=0.0002)$, between the daily use of hearing aids and the type of hearing aids $(p=0.0326)$, and between the gender of subjects and the benefits perceived by hearing aids $(p=0.0168)$. These relationships indicated that subjects with a greater degree of hearing loss (78\%) used their hearing aid(s) more often. BTE hearing aid users (71.05\%) wore their hearing aid(s) for more than 8 hours daily, while those $(56.52 \%)$ with ITE hearing aid(s) wore theirs less often. Women $(91.18 \%)$ reported receiving more benefits from hearing aid(s) than men (33.33\%). These significant relationships are displayed in Figure 2.

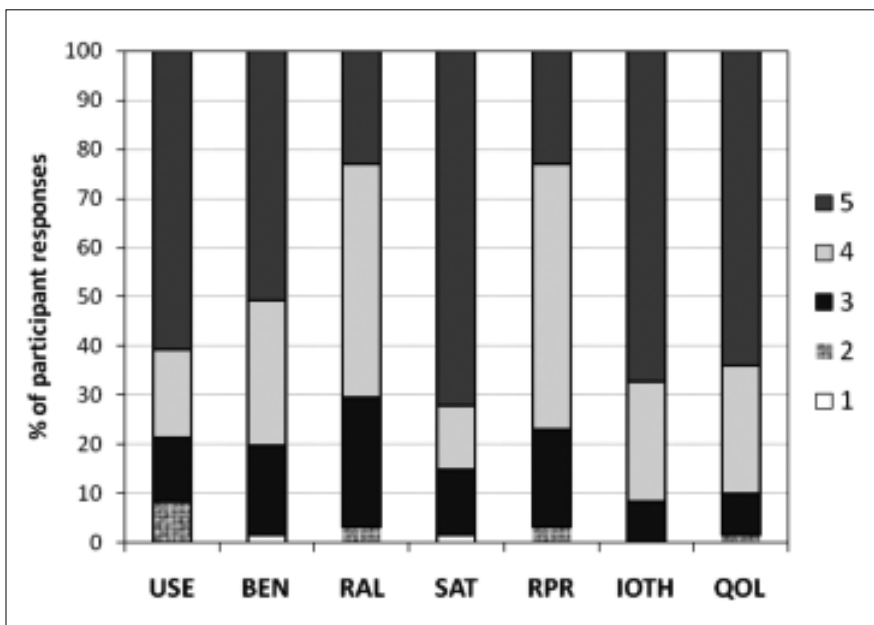

Fig. 1. Distribution of responses for the seven IOI-HA domains $(1=$ poorest outcome; 5 = best outcome) (USE = daily use; BEN = benefit; $R A L=$ residual activity limitations; $S A T=$ satisfaction; $R P R=$ residual participation restriction; $I O T H=$ impact on others; $Q O L=$ quality of life).

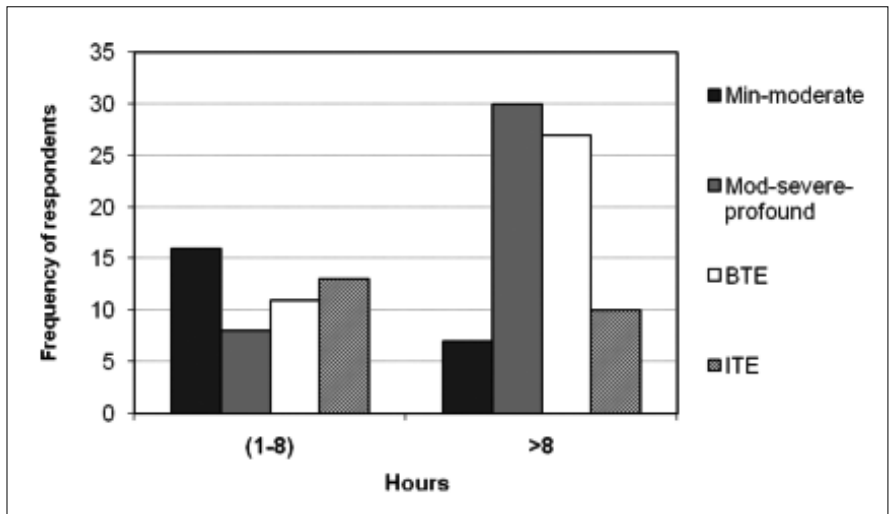

Fig. 2. Degree of hearing loss and type of hearing aid compared with daily use of hearing aid(s) (BTE = behind the ear; ITE = in the ear).

\section{Discussion}

In South Africa the majority of the population with hearing loss cannot afford audiological services in private practice and therefore rely solely on the public health care sector (Swanepoel, 2006). This sector and developing countries in general face a number of challenges, including a shortage of hearing aids and insufficient numbers of hearing health care professionals (Swanepoel, 2006; Punch, 2001; WHO, 2001). Budget constraints in the public health care sector meant that the majority of participants in the current study were only offered monaural hearing aid fittings. Despite these challenges the overall self-reported aural rehabilitation outcomes in this study were very positive. Valuable insight into how the South African sample perceived the use of hearing aid(s) and the effectiveness of the aural rehabilitation process can be drawn from these findings.
The benefits delivered by a hearing aid are primarily determined by the extent to which it facilitates everyday communication. The significant benefits derived from hearing aid(s) by participants in this study, emphasise the importance and value of aural rehabilitation services in South Africa and for other developing settings. The overwhelmingly positive report of benefits perceived from hearing aid(s) in this study despite sub-optimal fittings is difficult to explain. It may in part be contributed to the sample representing a developing context where expectations may be lower because of a more accepting stance towards disabilities in African communities (Louw \& Avenant, 2002), which may have resulted in greater perceived benefits. Only a small percentage of participants (2\%) reported no benefit from the hearing aid(s). This may be due to a number of reasons including technical problems, monaurally fitted hearing aids as opposed to binaural fittings, or unrealistic expectations concerning the use of hearing aid(s) in this subset. Studies have demonstrated that novice hearing aid users may have unrealistic expectations about the benefits they will receive from amplification (Cox \& Alexander, 2000). The novice hearing aid user may hope for complete restoration of auditory function, i.e. high expectations. If these expectations are not met, individuals may perceive limited benefits and even reduce the frequency of hearing aid use (Saunders, Chisolm \& Abrams, 2005). These results highlight the importance of appropriate counselling on the part of the hearing health care professional, in order to ensure realistic expectations.

Gender differences influenced the outcomes of aural rehabilitation in the current study, with the majority of women (91\%) indicating real benefits from their hearing aid(s) compared with only one-third of male participants (33\%). In contrast, reports by Williams et al. (2009) and Cox and Alexander (2002) did not find any significant influence of gender on the IOI-HA measured outcomes of aural rehabilitation. An earlier study did however find that women were more likely to acknowledge hearing loss than men (Garstecki \& Erler, 1999). Women tend to attach greater value to communication in social situations and take part more actively in reducing their communication difficulties, and this may have contributed to the gender difference in the current study (Garstecki \& Erler, 1999). The difference may also reflect the population characteristics of the current study, being from a developing African context, compared with reports by Williams et al. (2009) and Cox and Alexander (2002) from developed countries.

Residual activity limitation reflects the degree of disability that persists after amplification (Olusanya, 2004). A large percentage of participants $(48 \%)$ reported still having slight difficulty in crucial situations where they expected their hearing aid(s) to be helpful. According to Olusanya (2004), the reasons for still perceiving activity limitation may be similar to those for poor benefits received from hearing aids such as technical issues or unrealistic expectations. The same may be true for the current study, in that participants may have expected their hearing aid(s) to ensure optimal hearing in all situations. The fact that participants were mainly fitted monaurally may also have contributed to difficulties in discriminating speech in the presence of background noise. Appropriate counselling should be central to the intervention process to ensure realistic expectations in the light of these specific challenges.

Kochkin (1994) associated satisfaction with the fulfilment of a need or a desire. Satisfaction is highly related to benefits achieved by wearing hearing aids. The building blocks of satisfaction can be categorised into six domains: cosmetic and self-image; sound quality; benefit; comfort and ease of use; cost; and service quality (Cox \& Alexander, 1999). Satisfaction in these areas will lead to a high level of overall satisfaction (Cox \& Alexander, 1999). Most of the participants (72\%) in this study were satisfied with their hearing aid(s). Use, benefit and satisfaction are the targeted outcomes for hearing aid fittings. Results indicated a high percentage in the use (61\%), benefit (51\%) and satisfaction (72\%) domains, representing evidence of effective aural rehabilitation. 
Most of the participants (77\%) in this study reported minimal or no restriction by their hearing difficulty in their daily life participation. These results suggest that hearing aid(s) lead to significant reduction in the handicapping effects of hearing loss in life situations as reported by Olusanya (2004). When evaluating the success of aural rehabilitation, the focus is most often on the residual participation restriction of the user, whereas the impact of hearing loss on the significant others of hearingimpaired people is often overlooked. A large percentage of participants (67\%) did not feel that their hearing difficulty was of any inconvenience to those they interacted with while wearing their hearing aid(s). Eight per cent, however, felt that their significant others were affected by their hearing loss. According to the quality of life measure the majority (64\%) of participants indicated the highest outcome score (5) for a significantly improved quality of life due to their hearing aid(s). Hearing impairment has adverse effects on physical, cognitive, emotional, behavioural and social functioning, which are all contributors to quality of life (Barton, Bankart \& Davis, 2005). The use of hearing aids may lessen depression, reduce negative emotions and improve psychosocial function, thus improving quality of life (Kochkin \& Rogin, 2000).

Figure 3 provides a comparison with results from the current study and those of similar studies conducted in developed and developing countries (Table I provides the methodological differences between these studies). This cross-country comparison indicates that South Africa presented with the best overall perceived benefits and satisfaction scores. This is despite the fact that the participants in the current study were faced with the limitations of a developing context and the public health care sector (i.e. monoaural hearing aid fittings). This may be explained in part by the fact that benefits and satisfaction are closely related to expectations (Gatehouse, Naylor \& Elberling, 2003). Expectations related to hearing aids in a developing South African context may have been lower than in developed contexts. These lower expectations are then met far beyond conjecture, causing subjective benefits and satisfaction to be high (Bille \& Parving, 2003). Providing adequate aural rehabilitation services, even if not state-of-the-art, in developing contexts such as South Africa, may still result in significant outcome benefits to the affected individuals.

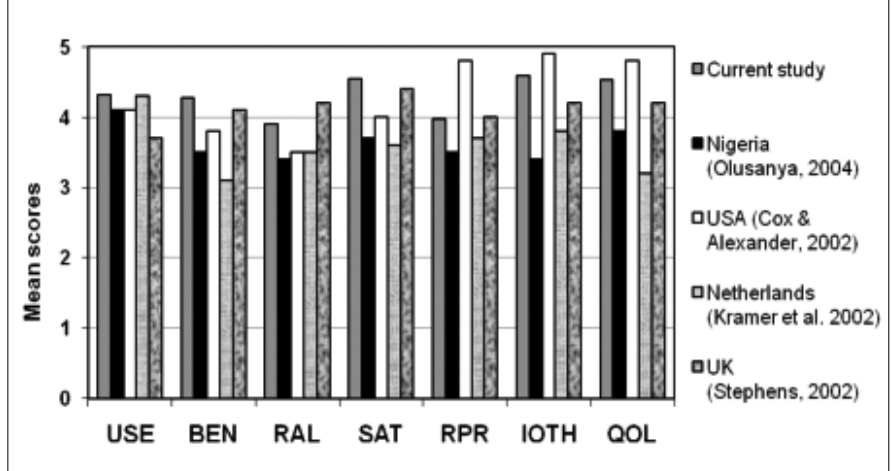

Fig. 3. Cross-country comparisons based on mean scores on IOI-HA items ( $1=$ poorest outcome; 5 = best outcome) (USE = daily use; BEN = benefit; RAL =residual activity limitations; $S A T=$ satisfaction; $R P R=$ residual participation restriction; IOTH = impact on others; $Q O L=$ quality of life).

Disability, or hearing impairment, cannot be seen as an exclusive feature of the individual. The focus is not only on the hearing-impaired individual, but also on the environment in which the person lives, and society at large (Schneidert, Hurst, Miller \& Ustun, 2003). Nonaudiological variables will undoubtedly influence the outcomes of audiological rehabilitation, such as personality, self-efficacy, social support, attitudes towards hearing aids and health status (manual dexterity) (Kricos, 2000). In the multi-cultural context of South Africa, different perceptions of disabilities may also influence the outcomes of rehabilitation, since a more fatalistic outlook that leads to a passive accepting attitude towards hearing loss may be a characteristic of African families (Louw \& Avenant, 2002). Investigations of the perceptions of disability, specifically hearing loss, among various populations in developing contexts are necessary to provide better insight into the benefits that patients may perceive. This may also provide a better understanding of the reasons for outcomes that are comparable to those in developed countries despite sub-optimal amplification.

\section{Conclusion}

By reporting the subjective opinions of hearing-impaired individuals, this study provides evidence that hearing aid(s) greatly improve quality of life for individuals relying on the public health care system in South Africa. Although the majority of the sample from this study was fitted monaurally, the perceived outcomes were still very positive, especially for women, who demonstrated better-perceived outcomes. Participants were satisfied with and reported benefit from their hearing aid(s), and experienced an increased enjoyment of life. The study indicated that aural rehabilitation in a public health care facility, even without optimal hearing aid fittings, was effective in providing positive perceived patient benefit. These findings advocate for the initiation of affordable and sustainable aural rehabilitation services in developing countries. Implications for clinical practice include the reassurance that intervention in the form of amplification, despite other challenges including sub-optimal fittings typical of resource-poor contexts, may still offer significant benefit to patients. Hearing-impaired individuals gain much benefit from audiological rehabilitations. Furthermore, counselling remains essential in this process and may need to be adjusted to address the specific concerns of male users to ensure optimal outcomes in this population.

Limitations of the current study include the fact that participants were sampled from only one hospital and not from more diverse sectors of the South African health care services. In addition to this limitation, two data collection techniques were used, a questionnaire and interview, which may have influenced results to some degree. Despite these limitations, results compared favourably with similar studies conducted in developed and developing countries (Kramer et al., 2002; Cox \& Alexander, 2002; Stephens, 2002; Olusanya, 2004).

\section{References}

Alpiner, J. G., \& McCarthy, P. A. (2000). Rehabilitative audiology: Children and adults. (3rd ed.). Philadelphia: Lippincott Williams \& Wilkins.

Barton, G. B., Bankart, J., \& Davis, A. C. (2005). A comparison of the quality of life of hearing impaired people as estimated by three different utility measures. International Journal of Audiology, 44, 15-163.

Bille, M., \& Parving, A. (2003). Expectations about hearing aids: demographic and audiological predictors. International Journal of Audiology, 42, 481-488.

Cox, R.M., \& Alexander, G.C. (1999). Measuring satisfaction with amplification in daily life: The SADL scale. Ear \& Hearing, 20, 306-320.

Cox, R.M., \& Alexander, G. C. (2000). Expectations about hearing aids and their relationship to fitting outcome. Journal of the American Academy of Audiology, 11, 368-382.

Cox, R. M., \& Alexander, G.C. (2002). The International Outcome Inventory for Hearing Aids (IOI-HA): psychometric properties of the English version. International Journal of Audiology, 41, 30-35.

Cox, R. M., Stephens, D., \& Kramer, S. E. (2002). Translation of the International Outcome Inventory for Hearing Aids (IOI-HA). International Journal of Audiology, 41, 3-26.

Danermark, B., Cieza, A., Gangé, J., Gimigliano F., Granberg, S., Hickson, L., et al. (2010). International classification of functioning, disability, and health core sets for hearing loss: A discussion paper and invitation. International Journal of Audiology, 49, 256-262.

De Vos, A. S., Strydom, H, Fouché, C. B., \& Delport, C. S. L. (2005). Research at grassroots: For the social sciences and human service profession (3rd ed.). Pretoria: Van Schaik.

Gagné, J. P. (2000). What is treatment evaluation research? What is its relationship to the goal of audiological rehabilitation? Who are the stakeholders of this type of research? Ear \& Hearing, 21, 60S-73S.

Garstecki, D. C., \& Erler, S. F. (1999). Older adult performance on the communication profile for the hearing impaired: Gender difference. Journal of Speech, Language, and Hearing Research, 42, 785-796.

Gatehouse, S. Naylor, G., \& Elberling, C. (2003). Benefits from hearing aids in relation to interaction between the user and the environment. International Journal of Audiology, 24, S77-S85.

Hickson, L. Clutterbuck, S., \& Khan, A. (2010). Factors associated with hearing aid fitting outcomes on the IOI-HA. International Journal of Audiology, 49, 586-595.

Kochkin, S. (1994). Letting the consumer drive your practice to excellence. Presented at the annual winter convention, Illinois Academy of Audiology, Chicago, IL.

Kochkin, S., \& Rogin, C. (2000). Quantifying the obvious: The impact of hearing instruments on the quality of life. The Hearing Review, 7, 6-34

Kramer, S. E., Goverts, S. T., Dreschler, W. A., Boymans, M., \& Festen, J. M. (2002). International Outcome Inventory for Hearing Aids (IOI-HA): results from The Netherlands. International Journal of Audiology, 41, 36-41.

Kricos, P. B. (2000). the influence of non-audiologial variables on audiological rehabilitation outcomes. Ear \& Hearing, 21 (4), 7S-14S.

Louw, B., \& Avenant, C. (2002). Culture as context for intervention: developing a culturally congruent early intervention program. International Pediatrics, 17 (3), 145-150.

National Treasury Department, Republic of South Africa. (2005). Intergovernmental fiscal review 2005. Retrieved from http://www.treasury.gov.za/publications/igfr/2005/default. aspx 12 March 2008). 
Northern, J. L., \& Downs, M. P. (2002). Hearing in children (5th ed). Philadelphia: Lippincott Williams \& Wilkins.

Olusanya, B. O. (2004). Self-reported outcomes of aural rehabilitation in a developing country. International Journal of Audiology, 43, 563-571.

Olusanya, B. O., Luxn, L. M., \& Wirz, S. L. (2004). Benefits and challenges of newborn hearing screening for developing countries. International Journal of Pediatric Otorhinolaryngology, 68(3), 287-305

Olusanya, B.O. (2005). State of the world's children: life beyond survival. Archives of Disease in Childhood, 90, 317-318.

Punch, J. (2001). Committee report: a low cost hearing aid for developing countries. Hearing International Newsletter, 36, 4-5.

Saunders, G.H., Chisolm, T. H., \& Abrams, H. B. (2005). Measuring hearing aid outcomes - not as easy as it seems. Journal of Rehabilitation Research and Development, 42 (4), 157-168.

Schneidert, M., Hurst, R., Miller, J., \& Ustun, B. (2003). The role of environment in the International Classification of Functioning, Disability and Health (ICF) Disability. Rehabilitation, 25 (11-12), 588-595.

Statistics South Africa. (2003). Bulletin of Statistics, 37(3), 1-280.

Stephens, D. (2002). The International Outcome Inventory for Hearing Aids (IOI-HA) and its relationship to the Client-orientated Scale of Improvement (COSI). International Journal of Audiology, 41, 42-47.
Swanepoel, D.W. (2006). Audiology in South Africa. International Journal of Audiology, 45, 262-266.

Tye-Murray, N. (2004). Foundations of aural rehabilitation: Children, adults and their family members (2nd ed). Clifton Park, NY: Thomson-Delmar Learning.

Vestergaard, M.D. (2006). Self-reported outcome in new hearing aid users: Longitudinal trends and relationships between subjective measures of benefit and satisfaction. International Journal of Audiology, 45, 382-392.

Williams, V. A., Johnson, C. E., \& Danhauer, J. L. (2009). Hearing aid outcomes: effects of gender and experience on patients' use and satisfaction. Journal of the American Academy of Audiology, 20, 422-432.

World Bank (2004). Introduction to selected world developments indicators: World Development Report 2004. London: Oxford University Press, 249-271.

World Health Organization (2001). Guidelines for hearing aids and services for developing countries. Geneva: WHO.

World Health Organization (2005). Preventing chronic diseases - a vital investment. Geneva WHO.

World Health Organization (2006). Working together for health - The World Health Report. Geneva: WHO.

\section{South African Journal of Communication Disorders}

Special Edition on Education: Past, present and future - SLT and audiology research and practice in developing contexts

Call for papers for publication in November 2011

\section{Editors:}

Harsha Kathard (Guest Editor-in-Chief)

Michelle Pascoe

This special edition of the SAJCD will focus on current research and practice of speech-language therapists (SLTs) and audiologists in education. The call for papers for a special edition arises from papers and discussions at the 2010 SASLHA conference that highlighted the critical need for speech, language, and hearing professions in supporting the development of communication and management of disorders for successful education for all South Africans.

Theoretical, methodological, review (literature and policy) and empirical papers are all invited for consideration across the disciplines of education, speech and language therapy, audiology, psychology and linguistics, with a particular focus on developing contexts including but not limited to South Africa.

\section{Submissions:}

To be submitted for publication, papers must be electronically uploaded to the SAJCD website http://www.sajcd.org.za/index. php/SAJCD by 28 February 2011. Please prepare manuscripts according to the guidelines shown on the website. All papers will receive a double-blind review following the usual review process. The special edition is scheduled for publication in November 2011. Any papers accepted for publication but not included in the special edition due to space constraints will be published later in a regular issue. For further information please contact the Editors, Harsha Kathard (harsha.kathard@uct.ac.za) or Michelle Pascoe (michelle.pascoe@uct.ac.za). 